\title{
PRODUTIVIDADE E QUALIDADE PÓS-COLHEITA EM FUNÇÃO DO RALEIO QUÍMICO DOS FRUTOS NO CULTIVO DA MACIEIRA CV. FUJI
}

\author{
Ana Maria Alves de Souza Ribeiro' \\ Bruna Bernades de Castro² \\ Bruno Farias Bonin ${ }^{3}$ \\ Giovanni Tomazelli Guesser ${ }^{4}$ \\ Leo Rufato ${ }^{5}$ \\ Andrea de Rossi Rufato 6
}

\begin{abstract}
Resumo: O objetivo do trabalho foi avaliar a influência do raleio químico dos frutos na produtividade e qualidade físico-química da macieira cultivar Fuji. O experimento foi implantado em 2011 e conduzido na Estação Experimental de Fruticultura de Clima Temperado (EFCT), pertencente à Embrapa Uva e Vinho, localizada no município de Vacaria, Rio Grande do Sul, na safra 2015/16. O delineamento utilizado foi o inteiramente casualizado, com 5 repetições, cujos tratamentos foram constituídos de diferentes porcentagens do ingrediente ativo do raleante químico tiossulfato de amônia (ATS): T1- Testemunha: sem aplicação do raleante químico tiossulfato de amônia (ATS), T2- Aplicação de 1,5 \% de ATS, T3- Aplicação de 2,5 \% de ATS, T4- Aplicação de 3,5\% de ATS. Com base nas avaliações realizadas conclui-se que o tiossulfato de amônia na concentração de 1,5\% apresentou melhores resultados para produtividade e frutificação efetiva, não afetando a concentração de sólidos solúveis totais, a firmeza da polpa e a incidência de "russeting" dos frutos de macieira cv. Fuji.

Palavras-chave: Malus domestica; Maçã; Produtos raleantes; Tiossulfato de amônia.
\end{abstract}

\footnotetext{
1 Universidade do Estado de Santa Catarina - UDESC, Brasil. E-mail: anamaria.acre@gmail.com.

2 Universidade do Estado de Santa Catarina - UDESC, Brasil. E-mail: bernardes-castro@bol.com.br.

3 Universidade do Estado de Santa Catarina - UDESC, Brasil. E-mail: brunofbonin@bol.com.br.

4 Universidade do Estado de Santa Catarina - UDESC, Brasil. E-mail: g.tomazelli.g@outlook.com.

5 Universidade do Estado de Santa Catarina - UDESC, Brasil. E-mail: leo.rufato@udesc.br.

${ }^{6}$ Embrapa Uva e Vinho/Fruticultura, Brasil. E-mail: andrea.rufato@embrapa.br.
} 